\title{
A weight restricted DEA model for FMEA risk prioritization
}

\author{
Pauli Adriano de Almada Garcia ${ }^{a *}$, Ilton Curty Leal Junior ${ }^{\mathrm{b}}$, Murilo Alvarenga Oliveira ${ }^{\mathrm{c}}$ \\ a*pauliadriano@id.uff.br, PUVR, Brasil \\ bilton@pet.coppe.ufrj.br, UFRJ, Brasil \\ 'malvarenga@id.uff.br, PUVR, Brasil
}

\begin{abstract}
In this paper we present a linear programming (LP) approach to risk prioritization in failure mode and effects analysis (FMEA). The LP is a data envelopment analysis (DEA)-based model considering weight restriction. In a FMEA, we commonly consider three criteria to prioritize the failure modes, occurrence, severity and detectability. These criteria are in an ordinal scale commonly varying from 1 to 10 , higher the figure worse the result. Considering the values established for each criteria, in traditional FMEA one adopts a Risk Priority Number, calculated considering the product of criteria, which has been very criticized due to its shortcoming. Through the proposed approach a frontier is established considering the less critical failure modes. Considering this frontier, one can establish how much each failure mode must be improved to become relatively acceptable. A simplified case concerning an AFWS of a two loops PWR power plant is presented to shows the applicability of the proposed approach.
\end{abstract}

Keywords

FMEA. Risk priority number. DEA. Weight restriction.

\section{Introduction}

Risk analysis is an activity which is commonly accomplished by reliability engineers and/or risk analysts from any industry. The results of a Probabilistic Safety Analysis (PSA) provides a lot of information to support the decision making process about maintenance policies or about care to be taken over some critical points of a system (FULLWOOD, 2000). The purpose of a failure mode and effect analysis (FMEA), in a PSA, is to find and supply semi-quantified information about the different ways that the system can fail, and constitute relevant inputs to the system modeling (INTERNATIONAL..., 1992). A FMEA can also be considered in the analysis of a service process, as in Oliveira, Paiva and Almeida (2010).

The data gathered through a FMEA should be considered in a decision making process concerning risk. The data which should have influence over the decision maker are associated with occurrence probability (0), severity of the respective effect (S) and with the potential to detect that something is going wrong. This potential is called detectability (D) (BOWLES, 1998; BOWLES; BONNELL, 1998).

Up to now, different approaches have been considered in turn to reduce the erroneous interpretation occasioned by the traditional risk priority number (RPN) (BOWLES; BONNELL, 1998, BOWLES, 2003).

The traditional RPN consist of the product of the three criteria, i.e., $\mathrm{RPN}=0 . \mathrm{S}$.D. These criteria are considered in an ordinal range, commonly, from 1 to 10 , the greater the order worse the case.

The problems concerning the RPN were firstly presented by Bowles and Peláez (1995, 1996). The main problem was associated with the importance of the severity criteria. For example, a failure mode with the following criteria, $0=1, S=10$ and $D=1$ is considered less important than one with $0=4$, $\mathrm{S}=4$ and $\mathrm{D}=4$. The former has an RPN $=10$ and the latter has a RPN $=64$, which will be prioritized. 
Bowles (2003) stated that from the 1000 possible RPN figures, only 120 are unique. For example, a $\mathrm{RPN}=64$ can be obtained from 10 different combination of $\mathrm{O}, \mathrm{S}$ and $\mathrm{D}$. Another shortcoming is that no RPN greater than 10 with a prime number as factor can be written as a product of three numbers. For example, 11, 22, 33, 990 and so on, for the same reasons, the multiples of $13,17,19$ etc.

With the intent of solving the above mentioned shortcoming, many different approaches have been established to ranking the failure modes. Bevilacqua, Braglia and Gabbrielli (2000) defined a different RPN as the weighted sum of six parameters (safety, equipment importance, maintenance cost, failure rate, repair time, and operational condition) multiplied by the seventh factor (difficulty to access the equipment). The relative importances of the six criteria are estimated by a paired comparison.

Braglia (2000) proposed a multi-attribute approach based on analytic hierarchical process (AHP) and named his approach Multi-Attribute Failure Mode Analysis (MAFMA). In this approach the risk factors (occurrence, severity, detectability and expected cost) are considered as decision attributes. The failure causes are considered the alternatives, and the selection of the failure causes is the main objective, which, together with the attributes and alternatives, composes a hierarchical structure of three levels. A matrix of pared comparison is considered to estimate the weight of the attributes and the priorities of the causes related to the respective expected cost.

Sankar and Prabhu (2001) presented a different approach based on a ranking from 1 to 1000 to represent the steps in risks, considering 1000 possible combinations to the criteria occurrence, severity and detectability. These combinations are tabled by an expert in an ascendant order and are interpreted by if-them roles, being that the highest figure should be prioritized in comparison to the other failure modes.

Garcia (2001), Garcia, Luz and Neves (2001) and Garcia, Neves and Neves (2001) presented some approaches based on data envelopment analysis (DEA) to prioritize the failure mode by means of a relative efficiency measure. The proposed approaches are based on a severity efficiency profile measure.

Chang, Liu and Wei (2001) considered a grey relational analysis to establish a grey relational degree between the failure modes and a target failure mode.

Many other approaches were published considering the uncertainty of the expert opinions. The majority of these works, in general, are based on fuzzy sets theory. Among these works are: (i) Bowles and Peláez (1995), which presented a fuzzy approach based on if-them roles. Some other works based on the proposition of Bowles and Peláez (1995) were published as, for example, Guimarães and Lapa (2004, 2007), Braglia, Frosolini and Montanary (2003) among others. (ii) Chang, Wei and Lee (1999) combine the concepts of fuzzy sets with grey relational analysis. (iii) Garcia, Schirru and Frutuoso and Melo (2005) and Garcia, Frutuoso and Melo and Schirru (2009) proposes a fuzzy DEA approach to prioritize the failure modes. (iv) Yang, Bonsall and Wang (2008) proposed a fuzzy rule-based Bayesian reasoning to prioritize the failure mode. (v) Chin et al. (2009) also proposed an approach similar to the one presented by Garcia, Luz and Neves (2001) and Garcia, Neves and Neves (2001). In his approach the authors propose a geometric mean considering the optimistic and pessimistic DEA results.

Based on the above explanation, the main purpose of the present work is to propose an approach based on a traditional constant return to scale DEA model, considering an output modeling (CHARNES; COOPER; RHODES, 1978). The contribution of the work for the risk analysis field is associated to the possibility of establishing guidelines in order to make improvements in the system under analysis. These guidelines are based on efficiency measures and can be concerned to quality, controls, safety and so on, depending of the purpose of the FMEA. The difference of the present work, compared to others which combine DEA with FMEA, is that the less critical failure modes will compose the efficiency frontier stated by DEA, being that, in the present work, these failure modes will be considered benchmarks for the most critical failure modes. With this approach, it will be possible to identify in which criteria and how much, among those considered in FMEA, the most critical failure modes should be improved to reach the frontier.

The guidelines established by the proposed approach may be a differential in the risk management process which, as stated by ISO 31010 (INTERNATIONAL..., 2009), must consider the following steps: (i) establishing the context, (ii) risk identification, (iii) risk analysis, (iv) risk evaluation, and (v) risk treatment. All the above steps are connected with communication and consultation, and with monitoring and review. In Figure 1, one can see a framework of the risk management process.

As stated by ISO 31000 (INTERNATIONAL..., 2009), monitoring and review are important to guarantee that the risk management is effective and continuous. In this way, performance measures should be established, as well as their verification comparing with the planned figures, verifying if the risk management policies are in consent with the internal and external context.

The proposed approach, considering an output DEA modeling to prioritize the failure modes, can help in the establishment of the performance measures and guide the improvement process. 


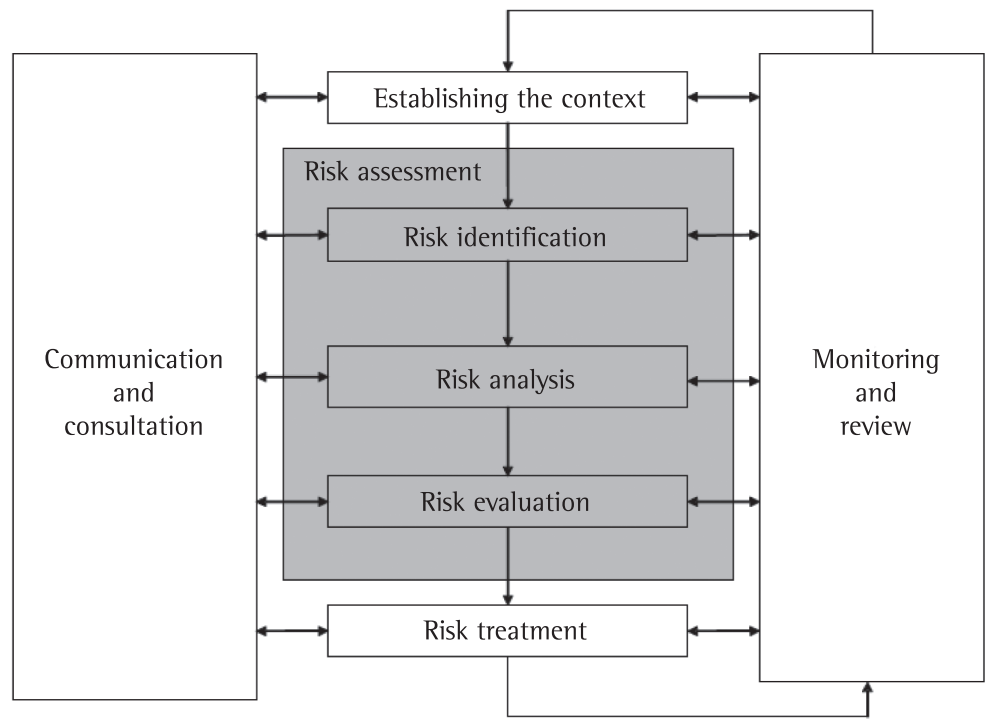

Figure 1. Contribution of risk assessment to the risk management process. Font: (INTERNATIONAL..., 2009).

The next section one presents some fundamental aspect of data envelopment analysis.

\section{Data envelopment analysis}

Charnes, Cooper and Rhodes (1978) began data envelopment analysis (DEA) in 1978 as an extension of the proposition of Farrel (1957). The presented model was based on linear programming whereas the objective is to maximize the output considering a level of input, or to minimize the inputs considering a level of output. The two formulations below were adapted from (CHARNES et al. 1994).

\section{Model 1 - output oriented}

\section{Max $h_{0}$}

s.t.

$x_{j 0}-\sum_{k=1}^{n} x_{i k} \lambda_{k} \geq 0, \forall i$

$-h_{0} y_{j 0}+\sum_{k=1}^{n} y_{j k} \lambda_{k} \geq 0, \forall j$

$\lambda_{k} \geq 0, \forall k$

\section{Model 2 - input oriented}

\section{$\operatorname{Min} h_{0}$}

s.t.

$h_{0} x_{j 0}-\sum_{k=1}^{n} x_{i k} \lambda_{k} \geq 0, \forall i$

$-y_{j 0}+\sum_{k=1}^{n} y_{j k} \lambda_{k} \geq 0, \forall j$

$\lambda_{k} \geq 0, \forall k$

In both models, $\mathrm{X}$ and $\mathrm{Y}$ are, respectively, the inputs and the outputs, $i$ is the number of inputs, $j$ is the number of outputs and $k$ is the amount of the Decision Making Units (DMU) considered in the analysis. The DMU, in this paper, will be the failure modes. The subscript 0 is referred to the DMU under evaluation. If the DMU is considered efficient then $h_{0}=1$, in our case it is not critical.

Nevertheless the above two formulations, the common approach is based on dual representation of the models 1 and 2. These dual representation, as presented by lins and Meza (2000), are concerned to the multiplier models.

Model 1 - Dual output oriented

$\operatorname{Min} h_{0}=\sum_{i=0}^{r} v_{i} X_{i 0}$

s.t.

$\sum_{j=1}^{s} u_{j} y_{j 0}=1, \forall i$

$\sum_{j=1}^{s} u_{j} y_{j k}-\sum_{i=1}^{r} v_{i} x_{i k} \leq 0, \forall k$

$u_{j}, v_{i} \geq 0, \forall i, j$

\section{Model 2 - Dual input oriented}

Max $h_{0}=\sum_{j=1}^{s} u_{j} y_{j 0}$

s.t.

$\sum_{i=1}^{r} v_{i} x_{i 0}=1$

$\sum_{j=1}^{s} u_{j} y_{j k}-\sum_{i=1}^{r} v_{i} x_{i k} \leq 0, \forall k$

$u_{j}, v_{i} \geq 0, \forall i, j$

For more details concerning the above DEA models, please refer to Charnes et al. (1994) or Cooper, Seiford and Tone (2007).

\section{Applying DEA models for FMEA}


To apply a DEA model as a technique for failure mode prioritization, one must consider: (i) the failure modes as DMU, (ii) the criteria $\mathrm{O}, \mathrm{S}$ and $\mathrm{D}$ as attributes to be considered in the efficiency evaluation. In Garcia, Luz and Neves (2001) and Garcia, Neves and Neves (2001) these criteria were considered as output and the idea was to prioritize the most critical failure modes. In this case, the formulation (3) was considered and the most critical failure modes will compose the frontier.

In the case whereas the criteria are considered as input, the idea is to find the less critical failure mode to compose the frontier. This approach will be considered in this paper and is an unpublished one.

For both the above mentioned approaches, one must consider a unitary input for the former case and a unitary output for the latter. This common factor can be interpreted as being the operational context.

To exemplify, let's consider the hypothetical failure modes presented in Table 1.

Considering the formulation 2, whereas S, 0 and $\mathrm{D}$ are inputs, we have the following prioritization of the FM:

Notice that the FM 1 is considered efficient, i.e., not relatively critical. However, its severity grade is the highest one. To make the prioritization proposed by DEA more realistic, we will consider the effect of weight restriction, i.e., the importance of the criteria will be differentiated in turn to consider the relevance of the severity criteria. Without loss of generality one will considers equally important the criteria occurrence and detectability. The severity will be considered more important than the two other criteria. So, the modeling will be:

$$
\begin{aligned}
& \text { Max } h_{0}=\sum_{j=1}^{s} u_{j} y_{j 0} \\
& \text { s.t. } \\
& \sum_{i=1}^{r} v_{i} x_{i 0}=1 \\
& \sum_{j=1}^{s} u_{j} y_{j k}-\sum_{i=1}^{r} v_{i} x_{i k} \leq 0, \forall k \\
& v_{s}-\left(v_{0}+v_{D}\right) \geq 0 \\
& u_{j}, v_{i} \geq \varepsilon \forall i, j
\end{aligned}
$$

In the formulation (5), the third restriction is concerned with the weight restriction in turn to establish a prioritization among the failure mode considering that the severity index is more important than the others two. $\varepsilon$ is a non-Archimedean figure, which should be as small as possible, considering the fact that the computer code must identify $\varepsilon$ as a number different from zero. This figure is convenient to make the model consider all the criteria. If $\varepsilon=0$, the model can consider one, or more, criteria as not important for the analysis.
Table 1. Hypothetical FMEA data.

\begin{tabular}{lclll}
\hline & Out 1 & S & 0 & D \\
\hline FM $^{*} 1$ & 1 & 9 & 3 & 2 \\
FM 2 & 1 & 3 & 5 & 5 \\
FM 3 & 1 & 4 & 6 & 5 \\
FM 4 & 1 & 5 & 4 & 6 \\
FM 5 & 1 & 4 & 3 & 3 \\
FM 6 & 1 & 2 & 5 & 4 \\
\hline
\end{tabular}

${ }^{*} \mathrm{FM}$ is the abbreviation of failure mode.

Table 2. Results of DEA application.

\begin{tabular}{cccccc} 
& Out 1 & S & 0 & D & DEA \\
\hline FM 1 & 1 & 9 & 3 & 2 & 1.000 \\
FM 2 & 1 & 3 & 5 & 5 & 1.000 \\
FM 3 & 1 & 4 & 6 & 5 & 0.725 \\
FM 4 & 1 & 5 & 4 & 6 & 1.000 \\
FM 5 & 1 & 4 & 3 & 3 & 1.000 \\
FM 6 & 1 & 2 & 5 & 4 & 1.000 \\
\hline
\end{tabular}

Table 3. Results of the proposed DEA model.

\begin{tabular}{cccccc}
\hline & Out 1 & S & 0 & D & DEA \\
\hline MF 1 & 1 & 9 & 3 & 2 & 0.58 \\
MF 2 & 1 & 3 & 5 & 5 & 1.00 \\
MF 3 & 1 & 4 & 6 & 5 & 0.70 \\
MF 4 & 1 & 5 & 4 & 6 & 1.00 \\
MF 5 & 1 & 4 & 3 & 3 & 1.00 \\
MF 6 & 1 & 2 & 5 & 4 & 1.00 \\
\hline
\end{tabular}

Applying the traditional DEA approach, the results of the data from Table 1 are presented in Table 2. The results associated to the proposed model are presented in Table 3.

Multiplying the DEA efficiency by the value of the respective inputs, one obtains the target value in turn to make the DMU under evaluation efficient. It signifies that the DMU must reduce the level of its input to become relatively efficient. For example, if one multiplies the inputs of MF1 by 0.58 this failure mode will become relatively efficient. This result is important, for example, in Layer of Protection Analysis (LOPA) or in a Safety Integrity Level (SIL) analysis.

The proposed model for the FMEA of an Auxiliary Feed Water System (AFWS) of Pressurized Water Reactor (PWR) power plant will be applied in the next section.

\section{Case study in a nuclear system}

The AFWS is composed of two subsystems: one has a turbine-driven pump (TDP) with the capacity of feeding the two steam generators (SGs), and the other subsystem is composed by two motor-driven pumps (MDPs), each one with the capacity of feeding 
one of the SGs. During normal alignment, the pumps use the water supplied from the auxiliary feed-water tank (AFWT). In a typical PWR plant, the AFWS should carry out the following basic functions:

- To feed the SGs in case of failure of the main feed water system;

- To maintain the water level in the SGs in order to remove the heat generated by the reactor, while the power level remains higher than 10\% or while there is residual heat being generated.

In Figure 2, the simplified structure of the AFWS used in this work is schematically displayed.

Considering the data from Guimarães and Lapa (2004), the simplified AFWS have 12 failure modes with the indexes presented in Table 4. More details about the failure modes from the AFWS refer to Guimarães and Lapa (2004).

Applying the model (5) to the data presented in Table 4 we obtain the results showed in Table 5.

These results shows that there are four failure modes considered as not critical. The two most critical failure modes are FM2 and FM3. Another observation is that from the twelve failure modes

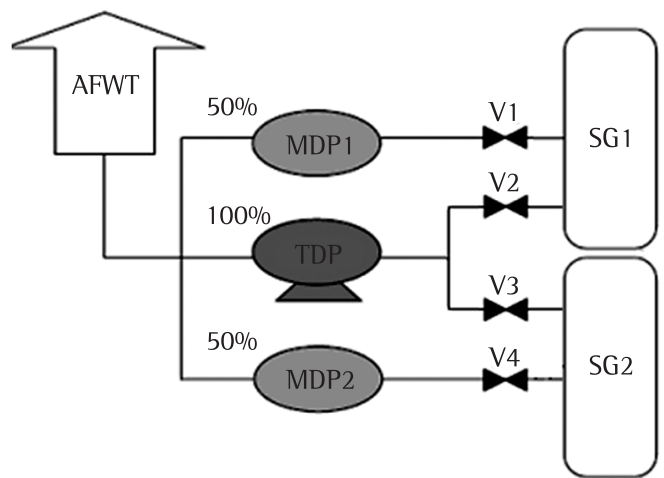

Figure 2. Simplified diagram of the AFWS.

Table 4. FWS FMEA data.

\begin{tabular}{ccccc}
\hline FM & O & S & D & Out \\
\hline FM1 & 3 & 2 & 8 & 1 \\
FM2 & 3 & 10 & 4 & 1 \\
FM3 & 3 & 10 & 4 & 1 \\
FM4 & 3 & 6 & 2 & 1 \\
FM5 & 3 & 6 & 2 & 1 \\
FM6 & 3 & 6 & 2 & 1 \\
FM7 & 4 & 8 & 2 & 1 \\
FM8 & 4 & 8 & 2 & 1 \\
FM9 & 6 & 4 & 4 & 1 \\
FM10 & 6 & 4 & 4 & 1 \\
FM11 & 6 & 6 & 4 & 1 \\
FM12 & 6 & 6 & 4 & 1 \\
\hline
\end{tabular}

one has six different combinations of $\mathrm{O}, \mathrm{S}$ and $\mathrm{D}$. From these, the model proposed a discrimination of five, i.e., the problem stated by Bowles (2003) was strongly softened by the proposed DEA model.

Based on the DEA results, one can establish improvements for the system considering the three criteria. Multiplying the input, i.e., the value of 0 , $\mathrm{S}$ and $\mathrm{D}$ by the efficiency value one obtains the target for the failure modes. Table 6 presents the improvements for the failure mode in turn to become relatively not critical.

Note that, in Table 6, the failure modes which were considered relatively non-critical, FM1 for example, don't have to improve the criteria, i.e., it is not necessary to reduce the value of $0, S$ and $D$ indexes. On the other hand, FM2, FM3, FM7, FM8, FM9, FM10, FM11 and FM12 must have their values of $\mathrm{O}, \mathrm{S}$ and D reduced. For example, FM11 and FM12 are associated to the turbo-driven-pump (TDP). These failures are on demand, i.e., when the TDP is demanded one can have a failure at the start of the engine or in the steam admission. The probabilities of occurrence of these failures are 7.1E-03/demand for both causes (GUIMARÃES; LAPA, 2004). For these

Table 5. Results of the proposed DEA model.

\begin{tabular}{cccccc}
\hline FM & 0 & S & D & Out & DEA \\
\hline FM1 & 3 & 2 & 8 & 1 & 1.000 \\
FM2 & 3 & 10 & 4 & 1 & 0.700 \\
FM3 & 3 & 10 & 4 & 1 & 0.700 \\
FM4 & 3 & 6 & 2 & 1 & 1.000 \\
FM5 & 3 & 6 & 2 & 1 & 1.000 \\
FM6 & 3 & 6 & 2 & 1 & 1.000 \\
FM7 & 4 & 8 & 2 & 1 & 0.813 \\
FM8 & 4 & 8 & 2 & 1 & 0.813 \\
FM9 & 6 & 4 & 4 & 1 & 0.843 \\
FM10 & 6 & 4 & 4 & 1 & 0.843 \\
FM11 & 6 & 6 & 4 & 1 & 0.717 \\
FM12 & 6 & 6 & 4 & 1 & 0.717 \\
\hline
\end{tabular}

Table 6. Improvement to the FM.

\begin{tabular}{cccc}
\hline FM & 0 & S & D \\
\hline FM1 & 3.000 & 2.000 & 8.000 \\
FM2 & 2.100 & 7.000 & 2.800 \\
FM3 & 2.100 & 7.000 & 2.800 \\
FM4 & 3.000 & 6.000 & 2.000 \\
FM5 & 3.000 & 6.000 & 2.000 \\
FM6 & 3.000 & 6.000 & 2.000 \\
FM7 & 3.252 & 6.504 & 1.626 \\
FM8 & 3.252 & 6.504 & 1.626 \\
FM9 & 5.058 & 3.372 & 3.372 \\
FM10 & 5.058 & 3.372 & 3.372 \\
FM11 & 4.302 & 4.302 & 2.868 \\
FM12 & 4.302 & 4.302 & 2.868 \\
\hline
\end{tabular}


FM to become relatively less critical, its actual indexes must be reduced from 6,4 and 6 to 4.302, 4.302 and 2.868 , respectively to $0, \mathrm{~S}$ and $\mathrm{D}$.

For example, considering the FM11 and FM12 again, reducing from 6 to 4.302 means that the probability of occurrence must be reduced to a value in the range [2E-03, 1E-03]. This range can be estimated if one considers a traditional reference Table 7.

The same analysis can be done considering the detectability index if one considers the Table 8 as reference.

Observing the Table 8 , one can infer that the probability of detecting the problem, i.e., the probability of the system, as a whole, to perceive a problem at the start of the engine or that a problem

Table 7. Reference table for the occurrence index.

\begin{tabular}{lcc}
\hline \multicolumn{1}{c}{ Occurrence } & Index & Probability estimate \\
\hline \multirow{2}{*}{ Inevitable } & 10 & $\geq 0,5$ \\
& 9 & 0,1 \\
Frequent & 8 & 0,05 \\
& 7 & 0,01 \\
Occasional & 6 & 0,02 \\
& 5 & 0,001 \\
Minor & 4 & 0,002 \\
Exceptionally & 3 & 0,0001 \\
\hline
\end{tabular}

Table 8. Reference table for the detectability index.

\begin{tabular}{lcc}
\hline \multicolumn{1}{c}{ Detectability } & Index & Probability estimate \\
\hline Very high & 1 & $86 \%$ to $100 \%$ \\
High & 2 & 76 to $85 \%$ \\
& 3 & 66 to $75 \%$ \\
Moderate & 4 & 56 to $65 \%$ \\
& 5 & 46 to $55 \%$ \\
Low & 6 & 36 to $45 \%$ \\
& 7 & 26 to $35 \%$ \\
Minor & 8 & 13 to $25 \%$ \\
& 9 & 6 to $15 \%$ \\
\hline
\end{tabular}

Font: Nunes (1999). concerning steam admission is imminent must be in the range of [76 to $85 \%$ ].

However, in light of Table 9, what does it mean to reduce the severity index from 6 to 4.302 ? If one considers a reference table as the following, a severity of 6 is in the same category of a severity of 4 . What does it mean? How should this result be interpreted? What if the proposed reduction, for example, leads to a category change? As stated before, the answer to this question is not easy.

In spite of the difficulties to interpret the proposed reductions of the severity index, at least one has guidelines for improvements.

\section{Conclusions}

The main purpose of the present work was to present a linear programming based approach to establish a priority ranking of failure modes. The criteria considered in the prioritization are the traditional Severity, Occurrence and Detectability indexes gathered through a FMEA.

The common approach is based on risk priority number which has been much criticized due to many problems related to numbers theory, as mentioned in the introduction section.

The proposed data envelopment model was based on the work of Garcia, Luz and Neves (2001) and Garcia, Neves and Neves (2001). In the model proposed in the present paper, the importance of the severity criteria was approached via weight restriction. This restriction states that the weight to be associated to the severity criteria must be greater than the weights of the occurrence and detectability criteria simultaneously.

Another important consideration was the non-Archimedean restriction. The purpose of this restriction is to ensure that all criteria will be considered in the analysis.

The obtained results, presented in section four, showed that one can establish, effectively, a priority ranking between the failure modes. It was also showed that it is possible to identify how much each criteria

Table 9. Reference table for the severity index.

\begin{tabular}{ll}
\multicolumn{1}{c}{ Severity } & \multicolumn{1}{c}{ Characteristics } \\
Very high & $\begin{array}{l}\text { The effect can affect both the safety and operation, as the environment, potentially causing damage to } \\
\text { property or persons and/or breaking any laws. } \\
\text { Reductions in the power level of the plant. } \\
\text { High }\end{array}$ \\
Roderate & $\begin{array}{l}\text { Reduce the system efficiency, generating work stresses which lead the plant to operate in level of risk over of } \\
\text { the one in normal condition. }\end{array}$ \\
Minor & The failure effects don't interfere in the plant operation, but reduce shortly the system performance. \\
Remote & The failure effect is almost not perceived.
\end{tabular}

Font: Nunes (1999). 
index must be reduced in turn to improve the system under analysis.

If one compares the proposed modeling with the different approaches presented in the introduction, none of the methods propose any kind of improvement to the system under evaluation. Traditionally, in a FMEA, the revision of the final worksheet is carried out based on recommendations stated in the first analysis. After completion of the proposed recommendations, the team must verify if they are effective. Based on this review, the team will reassess the indexes.

However, having the level of improvements, the main questions to be answered, as discussed in section four, are: (i) ls the introduction of redundancies in the system sufficient to reduce the 0 index? (ii) Can the introduction of more controls in the system reduce the D index? (iii) What must be done to reduce the $\mathrm{S}$ index?

The questions above can be answered by a Safety Integrity Level (SIL) analysis and can be important in a Layer of Protection Analysis (LOPA). In future works, the intent is to combine the proposed approach in the above mentioned analysis. It is important too, to apply the proposed approach to a higher amount of failure mode, i.e., to a FMEA of a more complex system.

Another important point is the consideration of expert opinions, which is a common issue in a FMEA. In future works one intends to approach this by a hybrid analysis considering fuzzy sets and DEA, as in Correia, Soares de Mello and Angulo Meza (2011).

\section{References}

BEVILACQUA, M.; BRAGLIA, M.; GABBRIELLl, R. Monte Carlo simulation approach for a modified FMECA in Power plant. Quality and Reliability Engineering International, v. 16, p. 313-324, 2000. http://dx.doi.org/10.1002/10991638(200007/08) 16:4<313::AID-QRE434>3.0.CO;2-U

BOWLES, J. B. An assessment of RPN prioritization in failure modes, effect and criticality analysis. In: IEEE PROCEEDINGS OF ANNUAL RELIABILITY AND MAINTAINABILITY SYMPOSIUM, 2003, Florida. Proceedings... Florida, 2003. 1 CD-ROM.

BOWLES, J. B. The new SAE FMECA standard. In: IEEE PROCEEDINGS OF THE ANNUAL RELIABILITY AND MAINTAINABILITY SYMPOSIUM, 1998, Anaheim. Proceedings... Anaheim, 1998. 1 CD-ROM.

BOWLES, J. B.; BONNELL, R. D. Failure mode, effect and criticality analysis: what it is and how to use it, In: TOPIC IN RELIABILITY AND MAINTAINABILITY AND STATISTICS, ANNUAL RELIABILITY AND MAINTAINABILITY SYMPOSIUM, 1998, Anaheim. Proceedings... Anaheim, 1998. 1 CD-ROM.

BOWLES, J. B.; PELAÉZ, C. E. Fuzzy logic prioritization in a system failure mode, effect and criticality analysis. Reliability Engineering and System Safety, v. 50, n. 2, p. 203-213, 1995. http://dx.doi.org/10.1016/09518320(95)00068-D

BOWLES, J. B.; PELAÉZ, C. E. Using fuzzy cognitive maps as a system model for failure modes and effect analysis. Information Science, v. 88, n. 1-4, p. 177-199, 1996. http://dx.doi.org/10.1016/0020-0255(95)00161-1

BRAGLIA, M. MAFMA: multi-attribute failure mode analysis. International Journal of Quality \& Reliability Management, v. 17, n. 9, p. 1017-33, 2000. http:// dx.doi.org/10.1108/02656710010353885

BRAGLIA, M.; FROSOLINI, M.; MONTANARY, R. Fuzzy criticality assessment model for failure modes and effect analysis. International Journal of Quality and Reliability Management, v. 20, n. 4, p. 503-524, 2003. http:// dx.doi.org/10.1108/02656710310468687

CHANG, C. L.; LIU, P. H.; WEl, C. C. Failure mode and effect analysis using grey theory. Integrated Manufacturing Systems, v. 12, n. 3, p. 211-216, 2001. http://dx.doi. org/10.1108/09576060110391174

CHANG, C. L.; WEl, C. C.; LEE, Y. H. Failure mode and effect analysis using fuzzy method and grey theory. Kybernetes, v. 28, p. 1072-1080, 1999. http://dx.doi. org/10.1108/03684929910300295

CHARNES, A.; COOPER, W. W.; RHODES, E. Measuring The Efficiency of Decision Making Units. European Journal of Operational Research, v. 2, p. 429-444, 1978. http:// dx.doi.org/10.1016/0377-2217(78)90138-8

CHARNES, A. et al. Data Envelopment Analysis: Theory, Methodology and Applications. Norwell: Kluwer Academic Publishers, 1994.

CHIN, K. S. et al. Failure mode and effects analysis using a group-based evidential reasoning approach. Computers and Operations Research, v. 36, n. 6, p. 1768-1779, 2009. http://dx.doi.org/10.1016/j.cor.2008.05.002

COOPER, W. W.; SEIFORD, L. M.; TONE, K. Data envelopment analysis: a comprehensive text with models, applications, references and DEA-solver software. 2nd ed. Springer, 2007.

CORREIA, T. C. V. D.; SOARES DE MELLO, J. C. C. B.; ANGULO MEZA, L. Assessment of Brazilian airlines technical efficiency: a study using data envelopment analysis and fuzzy sets. Produção, v. 21, n. 4, p. 676-683, 2011. http://dx.doi.org/10.1590/S0103-65132011005000049

FARRELL, M. J. The Measurement of Productive Efficiency. Journal of the Royal Statistical Society, Series A, part 3, p. 253-290, 1957. http://dx.doi.org/10.2307/2343100

FULLWO0D, R. R. Probabilistic risk assessment in chemical and nuclear industries. Woburn: ButterworthHeinemann, 2000.

GARCIA, P. A. A. Data envelopment analysis application in reliability centred maintenance process. 2001. $78 \mathrm{f}$. Dissertação (Mestrado em Sistema e Computação)Instituto Militar de Engenharia, Rio de Janeiro, 2001.

GARCIA, P. A. A.; FRUTUOSO E MELO, P. F. F.; SCHIRRU, R. A fuzzy-DEA model application for failure mode prioritization in nuclear systems. Pesquisa Operacional, v. 29, n. 2, p. 382-402, 2009

GARCIA, P. A. A.; LUZ, V.; NEVES, J. C. S. A DEA model application to failure mode prioritization, In: ENCONTRO NACIONAL DE ENGENHARIA DE PRODUÇÃO, 21., 2001, Salvador. Anais... Salvador, 2001a. 1 CD-ROM. 
GARCIA, P. A. A.; NEVES, J. C. S.; NEVES, G. C. DEA: a novel approach to failure mode evaluation in RCM, In: SIMPÓSIO DE PESQUISA OPERACIONAL E LOGÍSTICA DA MARINHA, 2001, Rio de Janeiro. Anais... Rio de Janeiro, 2001b. 1 CD-ROM.

GARCIA, P. A. A.; SCHIRRU, R.; FRUTUOSO E MELO, P. F. A fuzzy data envelopment analysis approach for FMEA. Progress in Nuclear Energy, v. 46, n. 3-4, p. 359-373, 2005. http://dx.doi.org/10.1016/j. pnucene.2005.03.016

GUIMARÃES, A. C. F.; LAPA, C. M. F. Effect analysis fuzzy inference system in nuclear problems using approximate reasoning. Annals of Nuclear Energy, v. 31, p. 107-115, 2004 http://dx.doi.org/10.1016/S03064549(03)00173-7

GUIMARÃES, A. C. F.; LAPA, C. M. F. Fuzzy inference to risk assessment on nuclear engineering systems. Applied Soft Computing, v. 7, p. 17-28, 2007. http://dx.doi. org/10.1016/j.asoc.2005.06.002

INTERNATIONAL ATOMIC ENERGY AGENCY - IAEA. Procedure for conducting probabilistic safety assessments of nuclear power plants (level 1): a safety practice. Vienna, 1992. IAEA Safety Series, n. 50, p. 4.

INTERNATIONAL ELECTROTECHNICAL COMMISSION - IEC. IEC 31010: Risk management - Risk assessment technique. Geneva, 2009.

INTERNATIONAL ORGANIZATION FOR STANDARDIZATION - ISO. ISO 31000: Risk management - principles and guidelines on implementation. Geneva, 2009. p. 26.

LINS, M. P. E.; MEZA, L. A. Análise envoltória de dados e perspectivas de integração no ambiente de apoio à decisão. Rio de Janeiro: COPPE/UFRJ, 2000.
NUNES, M. S. Análise dos modos e efeitos de falha de produto com utilização do desdobramento da função qualidade. 1999. Dissertação (Mestrado em Sistema e Computação)-Instituto Militar de Engenharia, Rio de Janeiro, 1999.

OLIVEIRA, U. R.; PAIVA, E. J.; ALMEIDA, D. A. de. Fault mapping integrated methodology: an approach to using process mapping with FTA and FMEA techniques, and supported by expert's critical analysis. Produção, v. 20, n. 1, p. 77-91, 2010 http://dx.doi.org/10.1590/S010365132010005000004

SANKAR, N. R.; PRABHUR, B. S. Modified approach for prioritization of failures in a system failure mode and effect analysis. International Journal of Quality and Reliability Management, v. 18, n. 3, p. 324-335, 2001. http://dx.doi.org/10.1108/02656710110383737

YANG, Z.; BONSALL, S.; WANG, J. Fuzzy rule-based Bayesian reasoning approach for prioritization of failures in FMEA. IEEE Transaction on Reliability, v. 57, n. 3, p. 517528, 2008. http://dx.doi.org/10.1109/TR.2008.928208

\section{Acknowledgements}

The authors are grateful to FAPERJ for supporting the research through the grants E-26/110.327/2011. We would also like to thank the anonymous reviewers for his/her thorough review and highly appreciate the comments and suggestions, which significantly contributed to improving the quality of the publication. 